\title{
A pós-graduação em CiênCIAS da Religião E TEOLOGIA NO QUADRIÊNIO 2013-2016
}

\author{
THE GRADUATE IN RELIGIOUS STUDIES AND \\ THEOLOGY IN 2013-2016 QUADRENNIUM
}

Flávio Senra *

\section{RESUMO}

O presente relatório se refere aos dados da pós-graduação em Ciências da Religião e Teologia no Sistema Nacional de Pós-graduação (SNPG), considerado o quadriênio de avaliação 20132016.

Palavras-chave: Ciências da Religião. Teologia. CAPES. Avaliação. Pós-graduação.

\section{ABSTRACT}

This report refers to the graduate data in the Religious Studies and Theology area in the National Graduate System (SNPG), considered the quadrennial of evaluation 2013-2016.

Keywords: Religious Studies. Theology. CAPES. Evaluation. Graduate Studies.

O presente relatório se refere aos dados da pós-graduação em Ciências da Religião e Teologia no Sistema Nacional de Pós-graduação (SNPG). A entidade responsável pelo acompanhamento da pós-graduação brasileira é a Coordenação de Aperfeiçoamento de Pessoal de Nível Superior (CAPES), uma Fundação vinculada ao Ministério de Educação do Brasil (MEC). No SNPG brasileiro, a pós-graduação está organizada em 49 áreas de avaliação.

A associação que reúne os programas de pós-graduação no país é a ANPTECRE - Associação Nacional de Pós-graduação e Pesquisa em Teologia e Ciências da Religião. Individualmente, os pesquisadores da área se organizam em outras sociedades científicas, sendo as maiores a SOTER - Sociedade de Teologia e Ciências da Religião e a ABHR - Associação Brasileira de História das Religiões.

A área de Avaliação em Ciências da Religião e Teologia surgiu com a Portaria CAPES 174/2016, publicada no Diário Oficial da União - DOU de 13 de outubro de 2016, redesignada pela Resolução $\mathrm{n}^{0}$ 01, de 04 de abril de 2017, publicada no Boletim de Serviço/CAPES - Edição Especial no 1 - abril 2017.

\footnotetext{
* Coordenador da área Ciências da Religião e Teologia na Capes (2016-2018/ 2018-2022). Coordenador da área Filosofia/Teologia na CAPES (2014-2016). Presidente do Conselho Diretor da ANPTECRE (biênios 2010-2012/2012-2014). Professor do Departamento de Ciências da Religião da Pontifícia Universidade Católica de Minas Gerais. Bolsista CNPq. Apoio CAPES. E-mail: flaviosenra@pucminas.br
} 
Com 46 anos de existência, desde a criação do mais antigo Programa da Área, os Programas da atual área de Ciências da Religião e Teologia compunham, até outubro de 2016, a extinta área Filosofia/Teologia: subcomissão Teologia.

A Área desenvolve investigações que se orientam por abordagem de perfil multidisciplinar, interdisciplinar ou transdisciplinar e abrange cursos de Mestrado Acadêmico, Doutorado e Mestrado Profissional.

A Área Ciências da Religião e Teologia reúne duas áreas de conhecimento, Teologia e Ciências da Religião. A árvore, contudo, se subdivide em oito subáreas que consideram a possibilidade de pesquisas na interface entre as duas áreas de conhecimento.

No quadro abaixo é possível identificar os temas correlatos a cada uma das subáreas acima apresentadas.

Quadro 1. Árvore do conhecimento

\begin{tabular}{|c|c|}
\hline SUBÁREA & TEMAS CORRELATOS \\
\hline $\begin{array}{l}\text { CIÊNCIA DA RELIGIÃO } \\
\text { APLICADA }\end{array}$ & $\begin{array}{l}\text { Religião e espaço público, política, ética, saúde, ecologia, } \\
\text { culturas; temas associados à div ersidade, respeito e tolerância; } \\
\text { diálogo inter-religioso; educação e religião. }\end{array}$ \\
\hline $\begin{array}{l}\text { CIÊNCIAS DA LINGUAGEM } \\
\text { RELIGIOSA }\end{array}$ & $\begin{array}{l}\text { Métodos e fontes para o estudo das religiões, espiritualidades } \\
\text { ou tradições de sabedoria, de suas línguas naturais, de seu } \\
\text { vocabulário e gramática; relações entre linguagem religiosa, } \\
\text { linguagem artístico-literária e linguagem em geral. }\end{array}$ \\
\hline $\begin{array}{l}\text { CIÊNCIASEMPÍRICAS DA } \\
\text { RELIGIÃO }\end{array}$ & $\begin{array}{l}\text { Fenômenos religiosos, espiritualidades, tradições de sabedoria } \\
\text { ou filosofias de vida no "campo”; disciplinas “... da religião”, em } \\
\text { diálogo com teorias e métodos de outras ciências constituídas: } \\
\text { Sociologia..., Antropologia..., Psicologia..., História..., Geografia } \\
\text {..., Fenomenologia..... - em sentido descritivo. }\end{array}$ \\
\hline $\begin{array}{l}\text { EPIST EMOLOGIA DASCIÊNCIAS } \\
\text { DA RELIGIÃO }\end{array}$ & $\begin{array}{l}\text { Reflexão teórico-metodológica ou metateórica; abordagens } \\
\text { filosóficas sobre o conceito/definição de religião ou sua } \\
\text { negação; psicologia da religião e fenomenologia da religião - } \\
\text { em sentido sistemático. }\end{array}$ \\
\hline $\begin{array}{l}\text { HIST ÓRIA DAST EOLOGIASE } \\
\text { RELIGIÕES }\end{array}$ & $\begin{array}{l}\text { Estudo histórico de ideias e doutrinas } \\
\text { religiosas/espiritualidades/tradições de sabedoria (história } \\
\text { intelectual), de sua(s) expressão(ões) ou arraigamento } \\
\text { sociocultural. }\end{array}$ \\
\hline $\begin{array}{l}\text { TEOLOGIA FUNDAMENTAL- } \\
\text { SIST EMÁTICA }\end{array}$ & $\begin{array}{l}\text { Fundamentação da teologia e seu desenvolvimento coerente } \\
\text { (sistemático); exposição do dogma (aspecto querigmático); } \\
\text { defesa ou clarificação atualizada das doutrinas } \\
\text { religiosas/espiritualidades/tradições de sabedoria específicas à } \\
\text { tradição (aspecto apologético); teologia política, teologia } \\
\text { filosófica; filosofia da religião. }\end{array}$ \\
\hline T EOLOGIA PRÁTICA & $\begin{array}{l}\text { Psicologia pastoral; ecoteologia, fé e política, homilética e } \\
\text { educação na respectiva tradição. }\end{array}$ \\
\hline $\begin{array}{l}\text { T RADIÇÕES E ESCRIT URAS } \\
\text { SAGRADAS }\end{array}$ & $\begin{array}{l}\text { Escrituras sagradas e relatos da tradição oral das diversas } \\
\text { tradições religiosas/espiritualidad es / tradições de sabedoria. }\end{array}$ \\
\hline
\end{tabular}


Ao final do quadriênio 2013-2016, a Área Ciências da Religião e Teologia contava com 21 programas de pós-graduação, distribuídos entre 8 programas de Ciências da Religião, 2 programas de Ciência da Religião, 2 programas de Ciências das Religiões e 9 programas de Teologia. Destes, 3 programas são da modalidade profissional e 18 programas são da modalidade acadêmico.

Quadro 2. Lista de Program as da área Ciências da Religião e Teologia no Brasil

\begin{tabular}{|l|l|l|}
\hline \multicolumn{1}{|c|}{ INST IT UIÇÃO } & NOME DO PROGRAMA & \multicolumn{1}{c|}{ CURSOS } \\
DE ENSINO SUPERIOR (IES) & & \\
\hline UEPA & CIÊNCIAS DA RELIGIÃO & MESTRADO \\
UFPB/J.P. & CIÊNCIAS DAS RELIGIÕES & MESTRADO/DOUTORADO \\
UNICAP & CIÊNCIAS DA RELIGIÃO & MESTRADO/DOUTORADO \\
UNICAP & TEOLOGIA & MESTRADO \\
FUFSE & CIÊNCIAS DA RELIGIÃO & MESTRADO \\
FUV & CIÊNCIAS DAS RELIGIÕES & MESTRADO PROFISSIONAL \\
PUC-RIO & TEOLOGIA & MESTRADO/DOUTORADO \\
UFJF & CIÊNCIA DA RELIGIÃO & MESTRADO/DOUTORADO \\
PUC/MG & CIÊNCIAS DA RELIGIÃO & MESTRADO/DOUTORADO \\
FAJE & TEOLOGIA & MESTRADO/DOUTORADO \\
PUC/SP & CIÊNCIA DA RELIGIÃO & MESTRADO/DOUTORADO \\
PUC/SP & TEOLOGIA & MESTRADO/DOUTORADO \\
PUCCAMP & CIÊNCIAS DA RELIGIÃO & MESTRADO \\
UMESP & CIÊNCIAS DA RELIGIÃO & MESTRADO/DOUTORADO \\
UPM & CIÊNCIAS DA RELIGIÃO & MESTRADO \\
PUC/PR & TEOLOGIA & MESTRADO/DOUTORADO \\
FT BP & TEOLOGIA & MESTRADO PROFISSIONAL \\
PUC/RS & TEOLOGIA & MESTRADO/DOUTORADO \\
EST & TEOLOGIA & MESTRADO/DOUTORADO \\
EST & TEOLOGIA & MESTRADO PROFISSIONAL \\
PUC-GOIÁS & CIÊNCIAS DA RELIGIÃO & MESTRADO/DOUTORADO \\
\hline
\end{tabular}

\section{Fonte: CAPES}

A Área se faz presente em todas as regiões do país, embora se observe uma assimetria nas regiões Norte e Centro Oeste. Cada uma destas regiões possui apenas um programa. A região Nordeste conta com 4 programas. A maior concentração de

1 UEPA - Universidade do Estado do Pará, UFPB/J.P. - Universidade Federal da Paraíba/João Pessoa, UNICAP - Universidade Católica do Pernambuco, FUFSE - Fundação Universidade Federal do Sergipe, FUV - Faculdade Unida de Vitória, PUC-RIO - Pontifícia Universidade Católica do Rio de Janeiro, UFJF - Universidade Federal de Juiz de Fora, PUC/MG - Pontifícia Universidade Católica de Minas Gerais, FAJE - Faculdade Jesuíta de Filosofia e Teologia, PUC/SP - Pontifícia Universidade Católica de São Paulo, PUCCAMP - Pontifícia Universidade Católica de Campinas, UMESP - Universidade Metodista de São Paulo, UPM - Universidade Presbiteriana Mackenzie, PUC/PR - Pontifícia Universidade Católica do Paraná, FTBP - Faculdade Teológica Batista do Paraná, PUC/RS - Pontifícia Universidade Católica do Rio Grande do Sul, EST - Faculdades EST (Escola Superior de Teologia), PUC-GOIÁS - Pontifícia Universidade Católica de Goiás. 
programas se observa nas regiões Sudeste e Sul, com 10 e 5 programas respectivamente.

A produção intelectual das áreas de avaliação da CAPES leva em consideração, entre outros aspectos, a produção acadêmica em produtos bibliográficos em livros e em periódicos científicos. Por um lado, a produção bibliográfica expressa em livros está distribuída em quatro estratos de menor a maior pontuação (L1 a L4). Os estratos L3 e L4 são considerados os estratos que caracterizam a produção qualificada em livros. Por outro lado, a produção bibliográfica em periódicos está distribuída em três faixas (B1-A2-A1, B5-B4-B3-B2 e C). A primeira faixa é relativa a produtos considerados de qualidade superior (B1 a A1). A segunda faixa relativa a produtos de qualidade inferior (B5 a B2). A terceira faixa $(\mathrm{C})$ se refere à produção não qualificada como artigo científico

A produção é avaliada em períodos de avaliação quadrienal. A última delas ocorreu no ano de 2017, relativo ao período (2013-2016). A seguir apresenta-se a evolução da produção intelectual qualificada, ou seja, aquela dos estratos superiores na avaliação de livros e de artigos em periódicos conforme explicado acima.

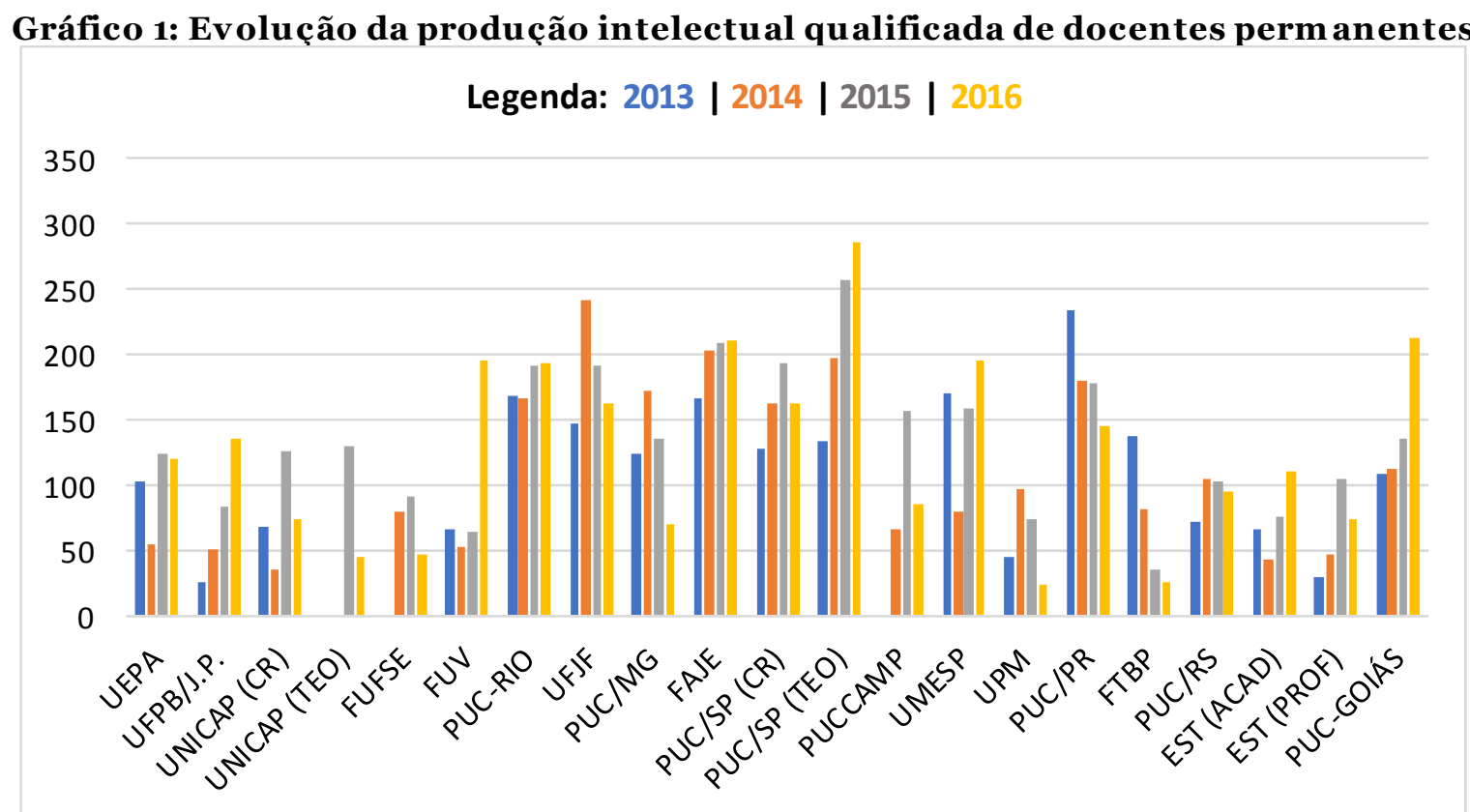

Fonte: CAPES

A produção intelectual qualificada, aferida pelos estratos superiores da avaliação em livros e em periódicos, apresenta o movimento que cada um dos programas de pós-graduação experimentou ao longo dos anos 2013-2016. 
Os estratos da produção bibliográfica conferem a cada um dos programas uma pontuação a partir dos estratos. Considerando os estratos superiores, sendo L3 e L4 para livros e B1, A2 e A1 para periódicos, o Gráfico 3 explicita o ranqueamento entre os programas.

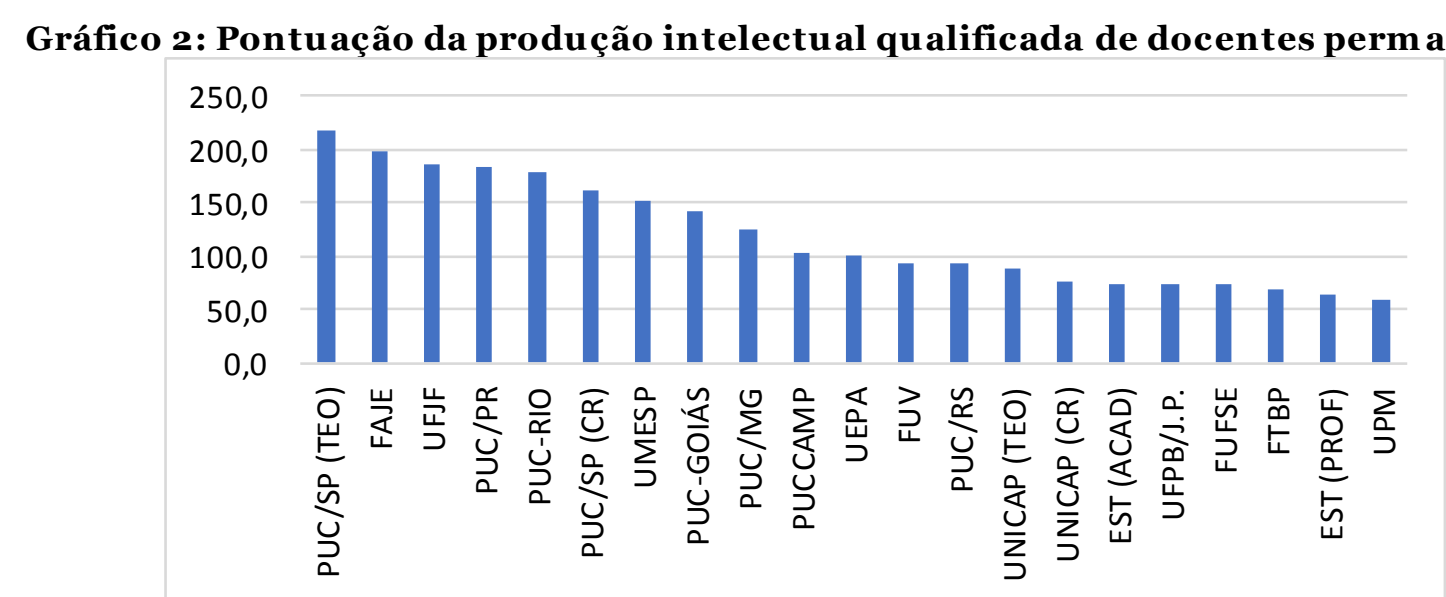

Fonte: CAPES, elaborado pela área a partir dos dados da Plataform a Sucupira

A produção técnica não está organizada por estratos e tampouco pode ser pontuada no atual sistema de avaliação da área Ciências da Religião e Teologia. Considerando a produção técnica dos programas, observa-se o volume do que foi produzido quanto a serviços técnicos, cursos de curta duração, apresentação de trabalhos, editoria, desenvolvimento de material didático, organização de evento, relatórios de pesquisa, dentre outros.

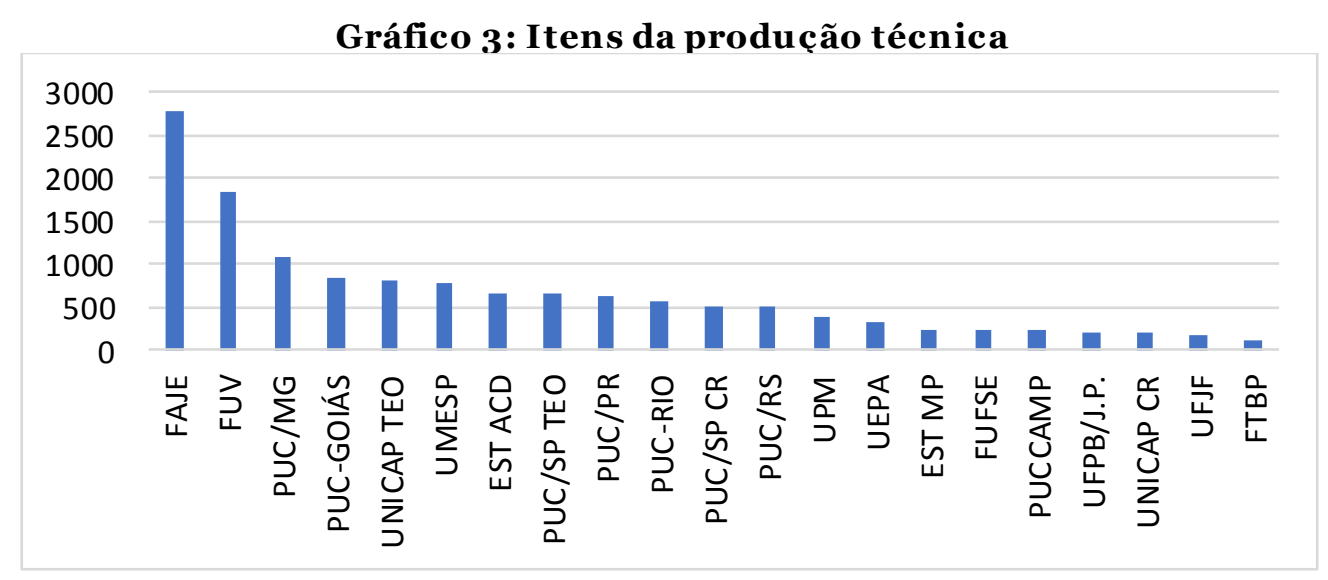

Fonte: CAPES

2 Pontuação conforme observação número 5, quesito 4, da Ficha de Avaliação dos PPGs Acadêmicos. Também foi aplicada aos PPGs com Mestrado Profissional. 
Assim como a produção de docentes, também a produção bibliográfica de discentes é avaliada. No gráfico 5, apresenta-se o volume de itens produzidos por discentes da área Ciências da Religião e Teologia.

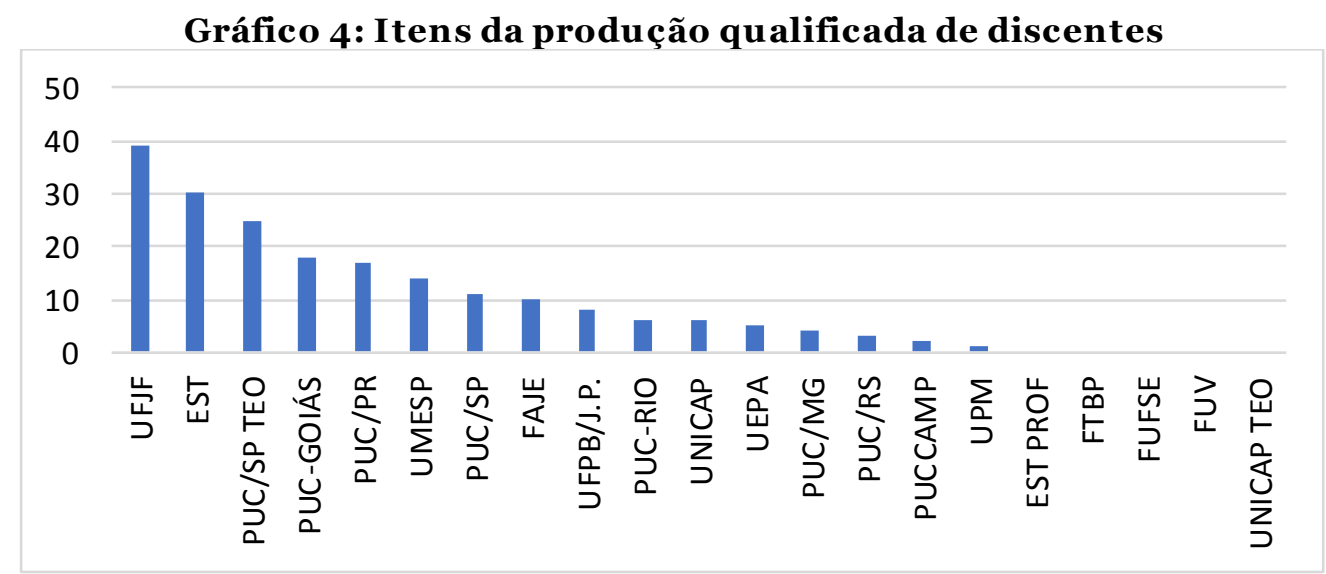

Fonte: CAPES

A área Ciências da Religião e Teologia obteve um crescimento de $22 \%$ no período 2013-2016, com quatro novos programas, sendo dois com cursos de Teologia e dois de Ciências da Religião. Destes, um é de Programa na modalidade profissional e três são da modalidade acadêmica (FTBP - Mestrado Profissional em Teologia, PUCCAMP - Mestrado Acadêmico em Ciências da Religião, FUSE- Mestrado Acadêmico em Ciências da Religião, UNICAP - Mestrado Acadêmico em Teologia).

Com relação às notas dos programas, após a avaliação periódica a cada quatro anos, têm-se os seguintes parâmetros: 1 e 2 (não aprovado), 3 (regular), 4 (bom), 5 (muito bom). As notas 6 e 7 referem-se a padrão de excelência.

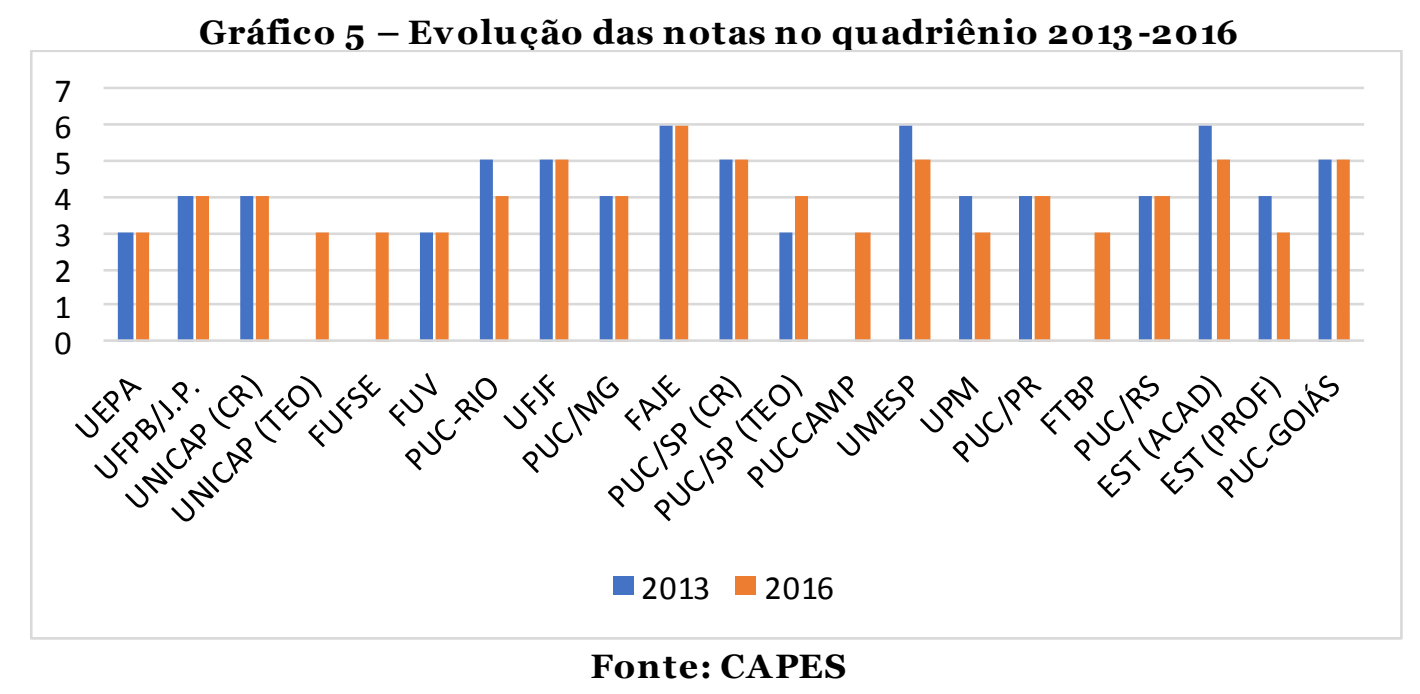


Os estudos pós-graduados em Ciências da Religião e Teologia estão ranqueados conforme a distribuição acima.

Estes são os dados que caracterizam o estado atual dos estudos pós-graduados em Ciências da Religião e Teologia no Brasil.

\section{REFERÊNCIAS}

COORDENAÇÃO DE APERFEIÇOAMENTO DE PESSOAL DE NÍVEL SUPERIOR. Classificação de livros. Área Teologia. Brasília, 23 jan. 2017. Disponível em: http://capes.gov.br/component/content/article/74-dav/caa2/4643-teologia Acesso em: 20 set. 2017.

COORDENAÇÃO DE APERFEIÇOAMENTO DE PESSOAL DE NÍVEL SUPERIOR. Consideraçốes sobre Qualis Periódicos 2016. Área Teologia. Brasília, 14 dez. 2016. Disponível em: http://capes.gov.br/component/content/article/74dav/caa2/4643-teologia Acesso em: 20 set. 2017.

COORDENAÇÃO DE APERFEIÇOAMENTO DE PESSOAL DE NÍVEL SUPERIOR. Critérios de APCN 2017 - Teologia. Área Teologia. Brasília, 22 nov. 2016.

Disponível em: http://capes.gov.br/component/content/article/74-dav/caa2/4643teologia Acesso em: 20 set. 2017.

COORDENAÇÃO DE APERFEIÇOAMENTO DE PESSOAL DE NÍVEL SUPERIOR. Critérios de APCN 2017. Área Teologia. Brasília, 18 nov. 2016. Disponível em: http://capes.gov.br/component/content/article/74-dav/caa2/4643-teologia Acesso em: 20 set. 2017.

COORDENAÇÃO DE APERFEIÇOAMENTO DE PESSOAL DE NÍVEL SUPERIOR. Documento de área e comissão da trienal 2013. Área Filosofia/Teologia. Brasília, 21 out. 2013. Disponível em: http://capes.gov.br/component/content/article/74-dav/caa2/4643-teologia Acesso em: 20 set. 2017.

COORDENAÇÃO DE APERFEIÇOAMENTO DE PESSOAL DE NÍVEL SUPERIOR. Documento de área 2017 . Área Teologia. Brasília, 22 nov. 2016. Disponível em: http://capes.gov.br/component/content/article/74-dav/caa2/4643-teologia Acesso em: 20 set. 2017.

COORDENAÇÃO DE APERFEIÇOAMENTO DE PESSOAL DE NÍVEL SUPERIOR. Documento Critérios APCNs 2017. Área Ciências da Religião e Teologia Disponível em http://www.capes.gov.br/ component/content/article/74dav/caa2/4643-teologia. Acesso em: 20 set. 2017.

COORDENAÇÃO DE APERFEIÇOAMENTO DE PESSOAL DE NÍVEL SUPERIOR. Portaria CAPES no 47, de 17 de outubro de 1995. RBPG, Brasília, v. 2, n. 4, p. 147148, jul. 2005. 
COORDENAÇÃO DE APERFEIÇOAMENTO DE PESSOAL DE NÍVEL SUPERIOR. Portaria CAPES no 147, de 13 de novembro de 2015. Diário Oficial da União, Brasília, 17 nov. 2015.

COORDENAÇÃO DE APERFEIÇOAMENTO DE PESSOAL DE NÍVEL SUPERIOR. Portaria 174, de 11 de outubro de 2016. Diário Oficial da União, Brasília, 13 out. 2016.

COORDENAÇÃO DE APERFEIÇOAMENTO DE PESSOAL DE NÍVEL SUPERIOR. Relatório de avaliação. Área Ciências da Religião e Teologia. Brasília, 20 set. 2017. Disponível em: http://capes.gov.br/component/content/article/74dav/caa2/4643-teologia Acesso em: 20 set. 2017.

COORDENAÇÃO DE APERFEIÇOAMENTO DE PESSOAL DE NÍVEL SUPERIOR. Resolução $\mathrm{n}^{\mathrm{O}}$ 1, de 4 de abril de 2017. Boletim de Serviço/CAPES, Brasília, Edição Especial $n^{0}$, abr. 2017.

MINISTÉRIO DA EDUCAÇÃO. Portaria no 389, de 23 de março de 2017. Diário Oficial da União, Brasília, 23 mar. 2017.

MINISTÉRIO DA EDUCAÇÃO. Portaria Normativa no 17, de 28 de dezembro de 2009. Diário Oficial da União, Brasília, 29 dez. 2009.

MINISTÉRIO DA EDUCAÇÃO. Portaria Normativa no 7, de 22 de junho de 2009. Diário Oficial da União, Brasília, 23 jun. 2009.

PLATAFORMA SUCUPIRA. Disponível em http://plataformasucupira.capes.gov.br Acesso em: 20 set. 2017.

SENRA, Flávio. Estudos de Ciência(s) da(s) Religião(ões) e Teologia no Brasil: Situação atual e perspectivas. Rever - Revista de Estudos da Religião. São Paulo, v. 15, no. 2, 2015.

SENRA, Flávio. O teólogo e o cientista da religião. Religiografia acerca das interfaces entre Ciências da Religião ou Religiologia e Teologia no Brasil. Rever - Revista de Estudos da Religião. São Paulo, v. 16, nº 1, 2016, p. 115.

SENRA, Flávio. Studies in Sciences of Religion and Theology in Brazil: Current Status and Perspectives. International Journal of Latin American Religion. Cham, Springer, v. 1, $\mathrm{n}^{\mathrm{O}} 1$ p. $24-41,2017$.

Recebido em: 16.12 .2018

Aprovado em: 23.12.2018 